\title{
Enzyme-linked Immunosorbent Assay for Screening the Plasma Residues of Tetracycline Antibiotics in Pigs
}

\author{
Hu-Jang LEE ${ }^{1)}$, Mun-Han LEE ${ }^{1) *}$, Pan-Dong RYU ${ }^{1)}$, Hang $\mathrm{LEE}^{1)}$ and Myung-Haing $\mathrm{CHO}^{1)}$ \\ ${ }^{1)}$ College of Veterinary Medicine and School of Agricultural Biotechnology, Seoul National University, Suwon 441-744, Republic of \\ Korea
}

(Received 24 May 2000/Accepted 23 January 2001)

ABSTRACT. The recommended therapeutic doses of three kinds of tetracyclines, oxytetracycline (OTC, withdrawal period, 10 days), chlortetracycline (CTC, withdrawal period, 5 days) and tetracycline (TC, withdrawal period, 5 days), were each administered to a group of 15 pigs. Blood was sampled before drug administration and during the withdrawal period. The concentration of tetracyclines in plasma, determined by semi-quantitative ELISA, was compared with that of internal standard (10 ppb as oxytetracycline). The absorbance ratio of internal standard to sample (B/Bs) was employed as an index to determine the tissue residues in pigs. All 45 plasma samples from nontreated pigs showed negative in the residue of any of three tetracycline antibiotics. OTC was detected in plasma of pigs treated until the 8th day, CTC until the 4th day, and TC was detected until the 3rd day of its withdrawal period. The present study showed that the semi-quantitative ELISA easily be adopted in predicting tissue residues for tetracycline antibiotics in live pigs.

KEY WORDS: live-animal screening test, porcine, tetracycline.

J. Vet. Med. Sci. 63(5): 553-556, 2001

Antimicrobial agents are widely used in animal husbandry for prophylactic and therapeutic purposes. Currently, approximately $80 \%$ of all food animals receive medication for part or most of their lives [17, 21]. In the future, nearly all animals produced in the world for food will receive a chemotherapeutic and prophylactic agent of some type [3]. A survey of all violative carcasses in the United States in 1993 revealed that the drugs most frequently creating residues were penicillin $(20 \%)$, streptomycin (10\%), oxytetracycline $(10 \%)$, sulfamethazine $(9 \%)$ and tetracycline (4\%) [20]. According to Canadian federal meat inspection testing programs, penicillins were the most frequently detected residues in tissues of pigs identified as suspect [12]. In Korea, the Department of Veterinary Service, Ministry of Agriculture \& Forestry, has conducted National Residue Program (NRP) of meat and poultry samples for antibiotic residues at slaughtering establishments under its inspection authority and from import shipments at the port of entry since 1986 . In 1997, a total of 45,000 samples comprising 10,000 beef, 23,000 pork and 11,000 poultry meat samples were analyzed for five kinds of antibiotics (penicillins and tetracyclines) and six sulfonamides. Violative residues of tetracyclines, sulfonamides and aminoglycosides were detected in beef and pork meat. Since tetracyclines are extensively used and have been reported to cause a high prevalence of multiresistant coliform organisms, the veterinarian should consider dosage regimens very carefully. The effect of feed-additive antibiotics on the time of Salmonella typhimurium shedding in the feces has been of much public health interest, since animals may serve as a reservoir of human salmonellosis [8].

\footnotetext{
* Correspondence to: Lee, M.-H., Laboratory of biochemistry, College of Veterinary Medicine, Seoul National University, Suwon 441-744, Republic of Korea.
}

Therefore, it is a very important public health problem to prevent antibiotic residue in foods. Reliable, simple, sensitive, rapid and low-cost methods for detecting residues in foods are needed [18]. Not only is there a need to develop rapid tests providing same-day results, but also to detect antimicrobials in biological fluids obtained preferably from live animals, which then can be used by primary producers in the field or in abattoirs. Variety of enzyme immunoassay technologies have been developed and adopted for detecting the generic groups of chemical residues in milk, urine, blood and meat samples $[6,14-16,22]$. ELISA has become the most popular for chemical residue detection in food due to its extreme sensitivity, simplicity and ability to screen large numbers of samples [4, 6, 17, 22]. Most residue assays commercially available for field applications are qualitative or semi-quantitative and are classified as screening assays. This requires that screening assays be developed with detection level optimized below the unsafe or violative levels (maximum residue limits) so that a violative sample will have a high probability of causing a positive test result $[5$, $6]$. In the present study, we developed a live animal test to predict the tissue residues of tetracycline antibiotics (OTC, CTC and TC) in swine by examining the drug depletion profile from blood during the withdrawal period obtained by an ELISA technique.

Animals used in this study were 45 healthy pigs weighing an average of $65 \mathrm{~kg}$ with no previous history of antibiotic treatment. A terramycin Injectable Solution $(50 \mathrm{mg} / \mathrm{ml}$ oxytetracycline hydrochloride, OTC) was purchased from Green Cross Animal Pharmaceutical Company (Seoul, Korea). Aurofac-B ${ }_{12}(110 \mathrm{~g} / \mathrm{kg}$ chlortetracycline hydrochloride, CTC) was obtained from Yuhan Corporation (Seoul, Korea). T-mycin (60 g/kg tetracycline hydrochloride, TC) was obtained from Dae-Sung Microbial Company (Seoul, Korea). ELISA kits for tetracyclines, manufactured by Ide- 
tek, were purchased from Korea Media Ltd. OTC was administered intramuscularly to each of 15 pigs at a dose of $10 \mathrm{mg}$ per $\mathrm{kg}$ body weight per day for consecutive 5 days. CTC was administered orally to each of 15 pigs at the rate of $1.1 \mathrm{~g}$ per $\mathrm{kg}$ feed per day for consecutive 5 days. TC was administered orally to each of 15 pigs at a dose of $100 \mathrm{mg}$ per liter water for consecutive 5 days. Blood samples were collected from all pigs before administration of the drugs and during the withdrawal period on the 1st, 2nd, 4th, 6th, 8 th and, 10th days after the last injection of OTC. From the pigs treated with CTC or TC, blood samples were collected on the $1 \mathrm{st}, 2 \mathrm{nd}, 3 \mathrm{rd}, 4 \mathrm{th}$ and 5 th days of the withdrawal period. Ten milliliters of blood from each pig was collected in heparinized tubes and centrifuged at $4,500 \times \mathrm{g}$ for $10 \mathrm{~min}$ to collect plasma. Stock standard solutions of $1,000 \mu \mathrm{g} / \mathrm{m} l$ of each of OTC, CTC and TC were prepared with USP standards in saline. These stock solutions were further diluted with plasma to prepare $1,10,50,100$ and $500 \mu \mathrm{g} / \mathrm{m} l$ working standard solutions. Standard curves of the antibiotics were constructed with standard solutions fortified with plasma to estimate the detection limit for the ELISA kit. ELISA for tetracyclines was applied to each plasma sample in duplicate by the method described by Boison et al. [2], who modified the manufacturer's protocol for milk screening and adapted for plasma screening.

The standard curves of OTC, CTC and TC were each constructed to determine the detection limit of each. As shown in Fig. 1, the detection limits of OTC, CTC and TC were lower than 10, 100 and $50 \mathrm{ppb}$, respectively, based on the $\mathrm{B} / \mathrm{Bo}$ ratio of 0.8 in the ELISA system.

The results of analysis for OTC in plasma are shown in Table 1. As the absorbance ratios of normal 15 pigs of the control group were greater than 1.0, that is, the concentrations of OTC in the diluted plasma $(\times 10)$ of this group were lower than $10 \mathrm{ppb}$ or negative. All samples showed positive results after the 1 st and the 2 nd days of withdrawal. After the 4th day of withdrawal, 14 of 15 samples were positive. The number of positive samples was eight on the 6th day, and seven on the 8th day of withdrawal. All samples showed negative reaction after the 10th day of withdrawal $(\mathrm{B} / \mathrm{Bs}$ ratio $\geq 1.0)$.

The results of analysis for CTC are shown in Table 2. As the absorbance ratios of normal 15 pigs of the control group were greater than 1.0, the concentrations of CTC in undiluted plasma of this group were lower than $100 \mathrm{ppb}$ or negative. All samples were positive on the 1 st day of withdrawal. On the 2 nd day of withdrawal, four of 15 samples were positive. The number of positive samples was two after the 3rd and the 4th days of withdrawal. After the 5th day of withdrawal, all samples showed negative reaction (B/ Bs ratio $\geq 1.0$ ). <Table 2>

The results of analysis for TC are shown in Table 3. As the absorbance ratios of normal 15 pigs of the control group were greater than 1.0, the concentrations of TC in undiluted plasma of this group were lower than $50 \mathrm{ppb}$ or negative. All samples showed positive results on the 1st day of withdrawal. On the 2 nd day of withdrawal, six of 15 samples

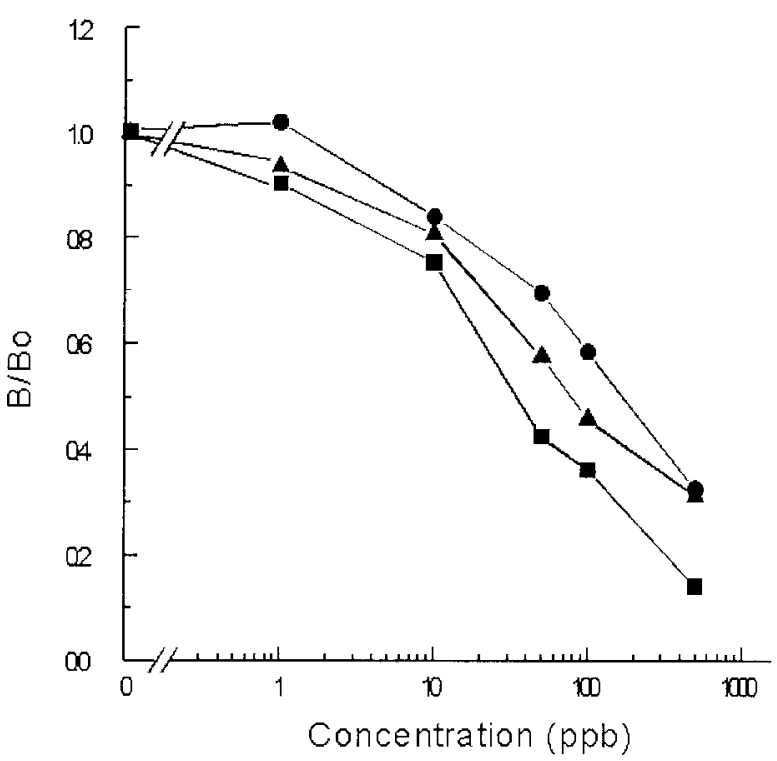

Fig. 1. Standard curves of tetracyclines in plasma. Detection limits of OTC ( $\boldsymbol{\square})$, CTC ( $)$ and TC ( $\boldsymbol{\Delta}$ ) were calculated at lower than 10, 100 and $50 \mathrm{ppb}$, respectively. The detection limit of the ELISA kit was decided with the point of B/Bo ratio 0.8. B/Bo: Absorbance ratio of standard (B) and saline or control plasma (Bo).

Table 1. Depletion profile of oxytetracycline in plasma during withdrawal period

\begin{tabular}{cccc}
\hline $\begin{array}{c}\text { Withdrawal } \\
\text { (days) }\end{array}$ & Positives & Negatives & $\begin{array}{c}\text { B/Bs ratio } \\
\text { (Mean } \pm \text { SD) }\end{array}$ \\
\hline Control $^{\text {a) }}$ & 0 & 15 & $1.112 \pm 0.049$ \\
1 & 15 & 0 & $0.538 \pm 0.119$ \\
2 & 15 & 0 & $0.666 \pm 0.070$ \\
4 & 14 & 1 & $0.860 \pm 0.090$ \\
6 & 8 & 7 & $0.977 \pm 0.062$ \\
8 & 7 & 8 & $1.015 \pm 0.104$ \\
10 & 0 & 15 & $1.083 \pm 0.051$ \\
\hline
\end{tabular}

a) Blood was collected before administration of OTC. The drug was administered intramuscularly with $10 \mathrm{mg} / \mathrm{kg}$ body weight once daily for consecutive 5 days and blood samples were collected from pigs during the withdrawal period. The concentration of OTC in diluted $(\times 10)$ plasma was analyzed with a LacTek ELISA kit. B is absorbance of sample and Bs is absorbance of internal standard (10 ppb).

were positive, and one of 15 samples was positive on the $3 \mathrm{rd}$ day of withdrawal. On the 4th day of withdrawal, all samples showed negative reaction $(\mathrm{B} / \mathrm{Bs}$ ratio $\geq 1.0)$.

Landoni and Errecalde [13] studied the distribution of a long-acting OTC formulation in the tissue after intramuscular administration to calves at a dose rate of $20 \mathrm{mg} / \mathrm{kg}$, and analyzed it in the muscle, kidney, fat, urine, bile, saliva and serum. Observed concentrations were higher than the minimal inhibitory concentration for the majority of microorganism tested in all of the analyzed tissues for at least $72 \mathrm{hr}$ post-injection. Hall et al. [7] studied to determine plasma 
Table 2. Depletion profile of chlortetracycline in plasma during withdrawal period

\begin{tabular}{cccc}
\hline $\begin{array}{c}\text { Withdrawal } \\
\text { (days) }\end{array}$ & Positives & Negatives & $\begin{array}{c}\text { B/Bs ratio } \\
\text { (Mean } \pm \text { SD) }\end{array}$ \\
\hline Control $^{\text {a) }}$ & 0 & 15 & $1.311 \pm 0.115$ \\
1 & 15 & 0 & $0.695 \pm 0.099$ \\
2 & 4 & 11 & $1.021 \pm 0.054$ \\
3 & 2 & 13 & $1.061 \pm 0.081$ \\
4 & 2 & 13 & $1.098 \pm 0.045$ \\
5 & 0 & 15 & $1.122 \pm 0.108$ \\
\hline
\end{tabular}

a) Blood was collected before administration of CTC. The drug was administered orally to each of 15 pigs at a rate of $1.1 \mathrm{~g}$ per $\mathrm{kg}$ feed on consecutive 5 days and blood samples were collected from pigs during the withdrawal period. The concentration of CTC in undiluted plasma was analyzed with a LacTek ELISA kit. B is absorbance of sample and Bs is absorbance of internal standard (100 ppb).

Table 3. Depletion profile of tetracycline in plasma during withdrawal period

\begin{tabular}{cccc}
\hline $\begin{array}{c}\text { Withdrawal } \\
\text { (days) }\end{array}$ & Positives & Negatives & $\begin{array}{c}\text { B/Bs ratio } \\
\text { (Mean } \pm \text { SD) }\end{array}$ \\
\hline Control $^{\text {a) }}$ & 0 & 15 & $1.319 \pm 0.076$ \\
1 & 15 & 0 & $0.684 \pm 0.072$ \\
2 & 6 & 9 & $1.040 \pm 0.104$ \\
3 & 1 & 14 & $1.096 \pm 0.073$ \\
4 & 0 & 15 & $1.195 \pm 0.088$ \\
5 & 0 & 15 & $1.205 \pm 0.075$ \\
\hline
\end{tabular}

a) Blood was collected before administration of TC. The drug was administered orally to each of 15 pigs at a rate of $100 \mathrm{mg}$ per liter of water for consecutive 5 days and blood samples were collected from pigs during the withdrawal period. The concentration of TC in undiluted plasma was analyzed with a LacTek ELISA kit. B is absorbance of sample and Bs is absorbance of internal standard (50 $\mathrm{ppb})$.

OTC concentration in pigs, and found that mean plasma concentration decreased to lower than $0.2 \mu \mathrm{g} / \mathrm{ml}$ by $72 \mathrm{hr}$ after intramuscular administration of $20 \mathrm{mg} / \mathrm{kg}$ body weight. Banting and Baggot [1] compared the pharmacokinetic properties of three OTC formulations in pigs following intramuscular injection of single doses $(20 \mathrm{mg} / \mathrm{kg}$ body weight). According to the results, the plasma concentrations of OTC at $48 \mathrm{hr}$ were $0.40-0.50 \mu \mathrm{g} / \mathrm{ml}$. Kilroy et al. [9] studied on the bioavailability and pharmacokinetic of CTC (IV, $11 \mathrm{mg} / \mathrm{kg}$ body weight) in pigs, and found that plasma CTC concentration was $0.10 \mu \mathrm{g} / \mathrm{ml}$ at $24 \mathrm{hr}$ of withdrawal. Kniffen et al. [10] studied in gilts the bioavailability and pharmacokinetic of TC (IV, $11 \mathrm{mg} / \mathrm{kg}$ body weight). They revealed that the mean plasma TC concentration was lower than $0.1 \mu \mathrm{g} / \mathrm{ml} 48 \mathrm{hr}$ of withdrawal. Nielsen and GyodHansen [19] measured the disposition of OTC $(10 \mathrm{mg} / \mathrm{kg}$ body weight), CTC (10 mg/kg body weight) and TC (10 mg/ $\mathrm{kg}$ body weight) after intravenous administration to pigs. OTC in plasma was higher than $0.05 \mu \mathrm{g} / \mathrm{ml} 24 \mathrm{hr}$ after administration, and CTC and TC were approximately 0.1 $\mu \mathrm{g} / \mathrm{ml} 30 \mathrm{hr}$. With the consideration of the dosage administered, the plasma concentrations profiles of tetracycline antibiotics in our study were similar to those in above stud- ies. As the withdrawal period of a drug is established based on the tolerance level in the tissue and the elimination rate of the drug, and blood is a central pool of drug distribution to body compartments [3], it may be able to predict the tissue residues of drugs in the tissue by examining the blood drug depletion profile during the withdrawal period $[2,11,14-$ 16]. According to our results, the developed methods can be adopted easily for use in prediction of tissue residues of OTC in live pigs by using diluted blood plasma $(\times 10)$ with the modified ELISA test kits. The concentrations of CTC and TC were too low to detect in diluted plasma during the withdrawal period. However, the current methods can be applicable on farm with undiluted plasma. It is conceivable that the veterinary inspector in the abattoir may be able to use this method to screen for tetracycline antibiotics in plasma of live pigs in holding pens prior to slaughter or on farm and to obtain same-day results. Pigs that show positive results can then be held in the pens until retest results become negative before they are slaughtered.

ACKNOWDGEMENTS. This work was partly supported by the Brain Korea 21 Project, a grant of Agricultural Research and Promotion Center, and a grant of the Veterinary Research Institute, College of Veterinary Medicine, Seoul National University, Korea.

\section{REFERENCES}

1. Banting, A. L. and Baggot, J. D. 1996. J. Vet. Pharmacol. Ther. 19: 50-55.

2. Boison, J. O., Korsrud, G. O., Papich, M. G. and MacNeil, J. D. 1995. J. AOAC Int. 78: 1144-1152.

3. Booth, N. H. 1988. pp. 1149-1205. In: Veterinary Pharmacology and Therapeutics, 6th ed. (Booth, N. H. and McDonald, L. E. eds.), Iowa State University Press, Ames, Iowa.

4. Clifford. M. N. 1985. pp. 3-10. In: Immunoassays in Food Analysis. Elsevier Applied Science Publishers, New York.

5. Cullor, J. S., Van Eenennaam, A., Gardner, I., Perani, L., Dellinger, J., Smit, W. L., Thompson, T., Payne, M. A., Jensen, L. and Guterbock, W. M. 1994. J. AOAC Int. 77: 862-870.

6. Gardner, I. A., Cullor, J. S., Galey, F. D., Sischo, W., Salman, M., Slenning, B., Erb, H. N. and Tyler, J. W. 1996. J. Am. Vet. Med. Assoc. 209: 46-52.

7. Hall, W. F., Kniffen, T. S., Bane, D. P., Bevill, R.F. and Koritz, G. D. 1989. JMVMA. 194: 1265-1268.

8. Huber, W. G. 1988. pp. 765-860. In: Veterinary Pharmacology and Therapeutics (Booth, N. H. and McDonald, L. E. eds.), Iowa State University Press, Ames, Iowa.

9. Kilroy, C. R., Hall, W. F., Bane, D. P., Bevill, R. F. and Koritz, G. D. 1990. J. Vet. Pharmacol. Ther. 13: 49-58.

10. Kniffen, T. S., Bane, D. P., Hall, W. F., Koritz, G. D. and Bevill, R. F. 1989. Am. J. Vet Res. 50: 518-21.

11. Korsrud, G. O., Salisbury, C. D. C., Fesser, A. C. E. and MacNeil, J. D. 1995. J. Food Prot. 58: 1129-1132.

12. Korsrud, G. O., Boison, J. O., Nouws, J. F. and MacNeil, J. D. 1998. J. AOAC Int. 81: 21-24.

13. Landoni, M. F. and Errecalde, J. O. 1992. Rev. Sci. Tech. 11: 909-915.

14. Lee, H. J., Lee, M. H. and Han, In K. 2001. Asian-Aust. J. Anim. Sci. 14: 378-381. 
15. Lee, H. J., Lee, M. H. and Han, In K. 2000. Asian-Aust. J. Anim. Sci. 13: 1775-1778.

16. Lee, H. J., Lee, M. H. and Han, In K. 2000. Asian-Aust. J. Anim. Sci. 13: 1604-1608.

17. Lee, M. H., Lee, H. J. and Ryu, P. D. 2001. Asian-Aust. J. Anim. Sci. 14: 402-413.

18. Mitchell, J. M., Griffiths, M. W., McEwen, S. A., McNab, W.
B. and Yee, A. J. 1998. J. Food Prot. 61: 742-56.

19. Nielsen, P. and Gyod-Hansen, N. 1996. J. Vet. Pharmacol. Therap. 19: 305-311.

20. Paige, J. C. 1994. FDA Vet. 9: 4-6.

21. Sternesjö, Å. and Sand G. J. 1998. J. Food Prot. 61: 808-811.

22. Szekacs, A. 1994. Acta Biol. Hung. 45: 77-80. 